\title{
Outer/inner morphology: The dichotomy of Japanese renyoo verbs and nouns
}

\author{
Mina Sugimura \& Miki Obata*
}

\begin{abstract}
This paper investigates the morpho-phonological differences between the nominal and verbal conjugational forms of renyoo (a preverbal form) in terms of (i) idiosyncrasy, (ii) productivity, and (iii) accent shift. All of these properties indicate that the two renyoo morphemes appear in different syntactic positions: with renyooverbs, the root first merges with the categorizer $v$ and then with the REN(yoo) head, whereas with renyoo-nouns, the root directly merges with the categorizer $n$, which is phonologically realized as the renyoo morpheme. Our analysis consequently supports Marantz's (2007) inner/outer morphology division within a word, and also provides implications for Chomsky’s (2013) $\{\mathrm{H}, \mathrm{H}\}$ Labeling Algorithm (Sugimura \& Obata 2014).
\end{abstract}

Keywords. renyoo forms; irregularity; productivity; word-internal domain; inner/outer morphology; labeling

1. Introduction. This paper provides an account for the fact that verbs and nouns of a certain conjugational form called renyoo (a preverbal form) behave quite differently morphophonologically and semantically despite their similarities on the surface (Tsujimura 1992, Volpe 2005). We propose that such differences arise from the 'closeness' between a root and what is associated with the renyoo inflectional morpheme, along the lines of Marantz's (2007) inner/outer contrast for morphology within a word. More specifically, we propose that the root is in the same domain as the renyoo morpheme in a noun, thus possibly undergoing 'irregular' morpho-phonological or semantic processes. However, the root is not in the same domain as the renyoo morpheme in a verb, hence always resulting in regular morphology or phonology as well as compositional semantics. The proposed account offers additional support for analyses exploiting word-internal syntax, such as Distributed Morphology (Embick \& Noyer 2007, Halle \& Marantz 1993, Harley \& Noyer 1999), while bringing out important implications for Chomsky's (2013) $\{\mathrm{H}, \mathrm{H}\}$ labeling mechanism, where a head merges with another head to create a syntactic object.

The paper is organized as follows: Section 2 lays out the basics of Japanese renyoo verbs and nouns, and presents intriguing linguistic facts associated with each of these renyoo forms. Section 3 proposes structures for renyoo verbs and nouns that account for their diverging behavior in terms of their morphology, phonology, and semantics. Section 4 discusses theoretical implications of our proposal while exploring an alternative analysis, to be rejected in the end. Section 5 concludes the paper.

2. Facts. Renyoo forms are one of the conjugational forms in Japanese that appear both in nouns and verbs. They typically take the form ' $\sqrt{R O O T}+i$, and their distribution is quite varied.

\footnotetext{
* We would like to express our gratitude to the attendants at our LSA poster presentation, especially Heidi Harley and Yohei Oseki for their insightful comments and encouraging feedback. We would also like to thank Bethany Lochbihler for her thorough editorial support and carefully thought out comments. All errors are entirely our own. Authors: Mina Sugimura, Kyoto Notre Dame University (sugimura@notredame.ac.jp) \& Miki Obata, Tokyo University of Science (obata@rs.tus.ac.jp).
} 
Below are some of the instances where renyoo forms emerge (see Tagawa 2012 for an extensive list of their distribution): ${ }^{1}$

$$
\begin{aligned}
& \text { Renyoo Verb Appearing in a Preverbal Position }{ }^{2} \\
& \text { Jun-ga tagemi-o kak-i, okur-ta. } \\
& \text { Jun-NOM letter-ACC write-REN send-PAST } \\
& \text { 'Jun wrote a letter and sent it.' }
\end{aligned}
$$

(3) Renyoo Noun Appearing in a Canonical Nominal Position
Haru-no os-i-ga yowai.
Haru-GEN push-REN-NOM weak
'Haru is not aggressive enough.'

As is obvious in (1) through (3), there are no apparent differences on the surface between renyoo verbs and nouns. In both forms, the root has the renyoo suffix $-i$ and functions either as a verb or a noun.

Despite their similarities on the surface, however, renyoo verbs and nouns behave quite differently from each other morpho-phonologically, and even semantically at times. In the following sections, we first show that they differ in terms of semantic interpretation and then point out that they also behave differently in terms of productivity. It is also revealed that they differ from each other in pitch accent assignment.

2.1. IDIOSYNCRASY. It has been observed in the literature that while renyoo verbs retain the core meanings of roots, renyoo nouns often yield idiosyncratic meanings (Volpe 2005):

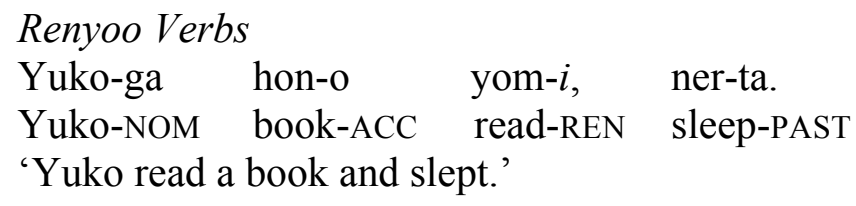

$$
\begin{aligned}
& \text { Renyoo Nouns } \\
& \text { Shin-no yom- } i \text {-ga } \\
& \text { Shin-GEN read-REN-NOM } \\
& \text { 'Shin's guess was right.' }
\end{aligned}
$$

In both (4) and (5) the root yom 'to read' takes its renyoo form. In (4) the renyoo verb yom- $i$ 'read-REN' is a conjunctive form and appears preverbally, whereas in (5) the renyoo noun yom- $i$ appears in the position where a noun normally occurs. As shown in the translation of each sentence, while the renyoo verb does not change its original meaning in (4), the renyoo noun often creates idiosyncrasy, as in (5). Therefore, yom- $i$ in (5) no longer has its original meaning 'a

\footnotetext{
${ }^{1}$ Vowel-ending roots such as $\sqrt{ }$ tabe 'to eat' are not accompanied by the vowel $-i$ in their renyoo forms, but instead appear with a null suffix (e.g. $\sqrt{ }$ tabe- $Ø$ ). We assume that the renyoo morpheme is phonologically conditioned and alternates between the $-i$ and null allomorphs.

2 The gloss abbreviations are as follows: $\mathrm{ACC}=$ accusative case; $\mathrm{COP}=$ copula; $\mathrm{GEN}=$ genitive case; $\mathrm{NOM}=$ nominative case; $\mathrm{PAST}=$ past tense; $\mathrm{REN}=$ renyoo morpheme; TOP=topic.
} 
read' but instead has the idiosyncratic meaning 'a guess'. The same pattern holds across a number of renyoo verb- and noun- pairs:

\begin{tabular}{|c|c|}
\hline Renyoo Verbs & Renyoo Nouns \\
\hline $\begin{array}{l}\text { a. nom-i 'someone drinks and...' } \\
\text { drink-REN }\end{array}$ & $\begin{array}{l}\text { b. nom-i 'alcohol drinking occasions' } \\
\text { drink-REN }\end{array}$ \\
\hline $\begin{array}{l}\text { c. nigir-i 'someone holds something and. } \\
\text { hold-REN }\end{array}$ & $\begin{array}{l}\text { nigir-i 'nigiri as in sushi' } \\
\text { hold-REN }\end{array}$ \\
\hline 'someone hits something and...' & $\begin{array}{l}\text { tatak-i 'seared/pound fish' } \\
\text { hit-REN }\end{array}$ \\
\hline $\begin{array}{l}\text { tor-i 'someone takes something and...' } \\
\text { take-REN }\end{array}$ & $\begin{array}{l}\text { tor-i 'last performer' } \\
\text { take-REN }\end{array}$ \\
\hline
\end{tabular}

The observed pattern here is thus that while renyoo verbs simply function as verbs in a conjunctive form and retain their original meanings, renyoo nouns often lose their original meanings and instead show semantic idiosyncrasy.

2.2. Productivity. Divergence between renyoo verbs and nouns is also seen in their productivity. Renyoo verbs are highly productive and any verb can take the renyoo form; however, renyoo nouns are far less productive than verbs, and their distributions are rather restricted (Volpe 2005): ${ }^{3}$

(7) Renyoo Verbs
a. kak-i
'Write-REN'
b. tat-i
'stand-REN'
c. utaw-i
'sing-REN'
d. moraw-i
'receive-REN'

(8) Renyoo Nouns
a. *kak-i
'Write-REN'
b. *tat-i
'stand-REN'
c. *utaw-i
'sing-REN'
d. *moraw-i
'receive-REN'

As observed in (7) and (8), any verbal root can take its renyoo form (7), but with renyoo nouns the exact same roots fail to appear in their renyoo forms (8). Thus, any root can appear in its conjunctive form and function as a verb, as in (9), but the same root cannot appear in a canonical nominal position or function as a noun as in (10):
a. Taro-ga
isu-kara tat-i,
waraw-ta.
Taro-NOM chair-from stand-REN smile-PAST
'Taro stood up from the chair and smiled.'

\footnotetext{
${ }^{3}$ We are very much aware of the fact that such 'unavailable' renyoo nominals become suddenly available once appearing in N-N compounds. For example, the ungrammatical * $k a k-i$ 'write-REN' becomes grammatical in yom-i $k a k-i$ 'read-REN write-REN' meaning 'reading and writing'. Likewise, *tat $i$ 'stand-REN' becomes good in a compound such as tat-i nom- $i$ 'stand-REN drink-REN' meaning 'standing around drinking'. Obviously, productivity mismatch in simple vs. compound words needs further research.
} 

b. Ziro-ga
sono
hon-o
kak-i,
seikoo-s-ta.
Ziro-NOM
that book-ACC
write-REN
success-do-PAST

'Ziro wrote that book and became successful.'
a. * Kono tukue-wa
tat-i-ga
warui.
this table-TOP
stand-REN-NOM bad
Intended Meaning: 'This table does not stand still.'
b. * Taro-no kak-i-wa heta-da.
Taro-GEN write-REN-TOP bad-COP
Intended Meaning: 'Taro's writing is bad.'

What has been shown thus far is that, on the one hand, renyoo verbs are highly productive and any root can take its renyoo form. On the other hand, renyoo nouns are much less productive and often result in ungrammatical forms.

2.3. ACCENT SHIFT. The last, but not least, property that distinguishes renyoo verbs and nouns is whether a lexically specified pitch accent shifts or not when a root appears in its renyoo form (Tsujimura 1992). As shown in (11), when forming a renyoo verb, the location of the pitch accent does not change, but when forming a renyoo noun, the accent shift occurs, as observed in (12):

$$
\begin{aligned}
& \text { (11) Renyoo Verbs (no accent shift) } \\
& \begin{array}{l}
\text { yóm } \rightarrow \text { yóm-i }(v) \\
\text { 'to read' read-REN }
\end{array} \\
& \text { (12) Renyoo Nouns }(\text { accent shift) } \\
& \text { yóm } \rightarrow \text { yom-í }(n) \\
& \text { to read' read-REN }
\end{aligned}
$$

In both (11) and (12), the stem yóm 'to read' has a lexically specified pitch accent. While the location of the accent stays the same when forming a renyoo verb in (11), an accent shift occurs when forming a renyoo noun and the accent falls on the suffix $-i$ in (12). Other verb-noun pairs, such as oyóg- $i(v)$ vs. oyog- $i(n)$ 'swim-REN' or nóm- $i(v)$ vs. nom- $i(n)$ 'drink-REN', present the same effect.

2.4. Summary. To summarize this section, we have seen that while renyoo verbs are well behaved and that no peculiar effects are observed with them, renyoo nouns show 'irregular' aspects, such as semantic idiosyncrasy, low productivity, and accent shift. In the following section, we associate this regular/irregular asymmetry between renyoo verbs and nouns with the domains within a word. More specifically, we argue that 'irregularity' is observed only in the inner domain of a word, but 'regularity' is strictly maintained in the outer domain of a word along the lines of Marantz (2007).

3. Proposal. In order to account for the divergence between renyoo nouns and verbs, we propose the following structures in (13a) and (13b), respectively: ${ }^{4}$

\footnotetext{
${ }^{4}$ Sugimura \& Obata (2014) have already proposed these decomposed structures for renyoo nouns and verbs. However, there we assume that the same number of layers is involved in both renyoo nouns and verbs, and that the categorical difference lies in the feature specification of the REN head, which we greatly depart from in this paper. See Sugimura \& Obata (2014) for details.
} 

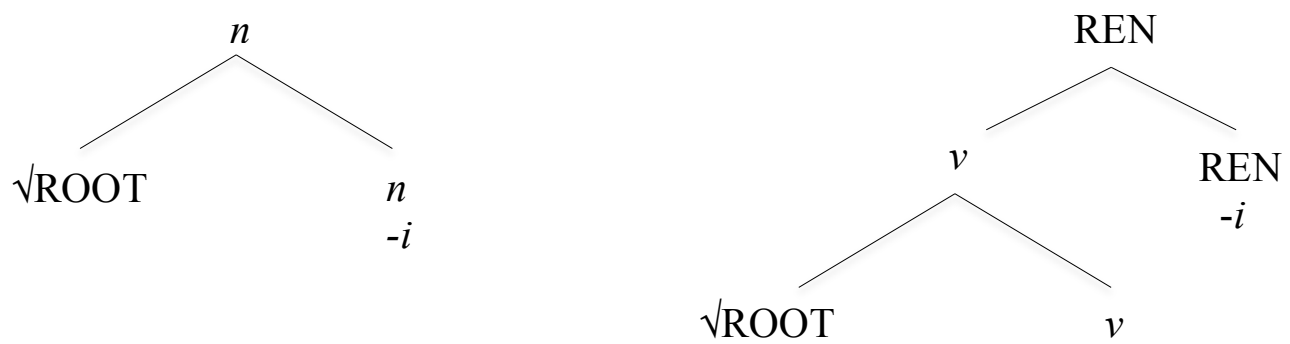

In (13a), a renyoo noun is formed by merging a root directly with the categorizer $n$, which is phonologically realized as $-i$. In (13b), a renyoo verb is formed by first merging a root with the categorizer $v$ and then the REN head, phonologically realized as $-i$. We assume, following Sugimura \& Obata (2014), that the vowel [i] is a phonological realization of the REN head and not an epenthetic vowel (cf. Tagawa 2012). ${ }^{5}$ Notice that in (13a) and (13b), the homophonous $-i$ appears in different syntactic positions. In fact, we argue that the observed difference between renyoo nouns and verbs discussed in Section 2 lies in the different syntactic position of the renyoo morpheme (see also Volpe 2005 for a similar approach). More specifically, we suggest that the proposed structures in (13a) and (13b) nicely reflect Marantz's (2007) inner vs. outer morphological domains, schematized below:

(14) Marantz's Inner/Outer Morphological Domains

\section{Inner morphology}

- can result in semantic idiosyncrasy

- can affect productivity

- can affect phonological realization

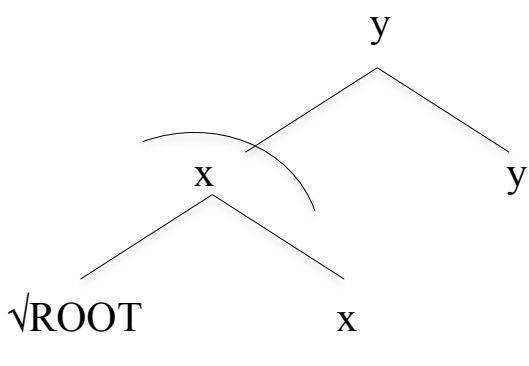

Outer morphology

- must be compositional

- must be productive

- cannot alter phonological properties of the root already determined

In the previous literature, the irregular/regular division in semantics and phonology has been associated with the lexical/syntactic dichotomy (e.g. lexical vs. syntactic causatives, taken up in Fodor 1970, Harley 1995, Miyagawa 1998, Shibatani 1990, and Travis 2000, among others). However, according to Marantz (2007), there is no such lexical/syntactic division in grammar, and such 'irregularity' or 'regularity' is associated with word-internal domains determined by the syntax. Marantz proposes that in (14) what is labeled as the inner domain, where the root directly merges with the category-determining head $x$, is where semantic idiosyncrasy and 'destructive' phonology can occur. However, once outside this inner morphological domain, semantic interpretations are strictly compositional and phonological properties already determined in the first cycle (i.e. the inner morphological domain) are preserved in the outer morphological domain (see also Newell 2008). ${ }^{6}$

\footnotetext{
${ }^{5}$ Volpe (2005) also assumes that the vowel [i] is a phonological realization of a syntactic head. Under his analysis, a root merges with an affixal element before it is categorized, and since the resulting structure belongs to the same cycle, it accounts for non-compositional semantics.

6 The term 'destructive phonology' is adopted from Dobler et al. (2009).
} 
Returning to the current dichotomy between renyoo verbs and nouns, we see that Marantz's inner/outer morphology correlates with the domain discrepancy between renyoo verbs and nouns. In other words, if we see a renyoo noun as an instance of inner morphology, its irregularity in terms of semantic interpretations, productivity, and accent shift, will naturally follow. Similarly, if we see a renyoo verb as an instance of outer morphology, its regularity in terms of all the aforementioned properties will also follow. (15) and (16) schematize each domain, respectively: ${ }^{7}$

Renyoo Noun as Inner Morphology ${ }^{8}$

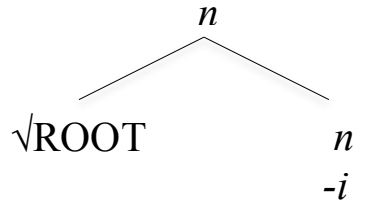

- idiosyncrasy

- low-productivity

- accent shift

Renyoo Verb as Outer Morphology ${ }^{9}$

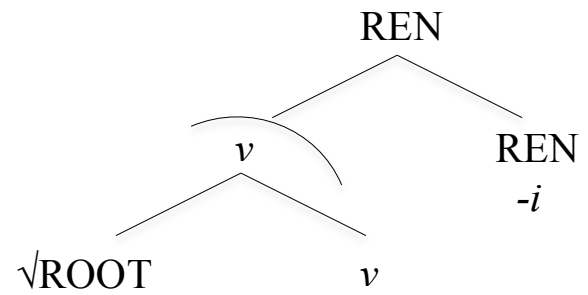

- compositionality

- productivity

- no accent shift

To summarize this section, we have proposed that renyoo nouns and verbs, despite their similarities on the surface, have fundamentally different structures. While a renyoo noun consists of a root directly merged with the categorizer $n$ (phonologically realized as $-i$ ), a renyoo verb involves an additional layer with a REN head (also realized as $-i$ ) above a root and the categorizing head $v$.

4. Consequences. The decomposed structure of a renyoo form has already been explored in Sugimura \& Obata (2014), but exclusively in the context of V-V compounds. We proposed that renyoo nouns and verbs essentially share the same structure in that a root directly merges with the REN head, which is categorically unspecified and needs to be provided a category through

\footnotetext{
${ }^{7}$ While we acknowledge that independent evidence for postulating a syntactic head such as REN is called for, we do not have additional support for the REN head at this point. Its theoretical implications, however, will be explored later in Section 4.

${ }^{8}$ As pointed out by Heidi Harley (p.c.), another possibility for a renyoo noun is that a root first merges with a REN head, and the $\left[\sqrt{ }\right.$ ROOT + REN] complex is then categorized by an $n$ head, resulting in the structure ${ }_{n}\left[{ }_{\text {REN }} \sqrt{ }\right.$ ROOT REN] $n$ ]. In this case, the REN head appears in both nouns and verbs, and the only difference is where it appears. This is in fact a possible alternative, and its implication is that the timing of 'spelling out' of the REN head differs in nouns and verbs. In verbs, the REN head is not in the same cycle as the root, hence the resulting regular morphology and semantics, but in nouns the REN head is necessarily in the same cycle as the root, thus the irregular morphology and idiosyncrasy follow (thanks to Yohei Oseki for pointing this out). Whether we associate the '(ir)regularity' with the same REN head in a different syntactic position or with a different head in a different position is worth pursuing, but we leave this issue for future research.

${ }^{9}$ Another possibility, pointed out by Yohei Oseki (p.c.) and also pursed in Sugimura (2012), is that renyoo verbs are nominalized 'verbs'. In this scenario, the suffix $-i$ in a renyoo form, whether a noun or a verb, is a realization of the $n$ head. That is, in renyoo nouns an $n$ head directly merges with a root, whereas in renyoo verbs an $n$ head merges with a $v(\mathrm{P})$ already merged with a root. Again, we remain open to this alternative and leave it for future research.
} 
feature-specification from a category-defining head. The relevant structures for both renyoo verbs and nouns are given in (17a) and (17b), respectively:
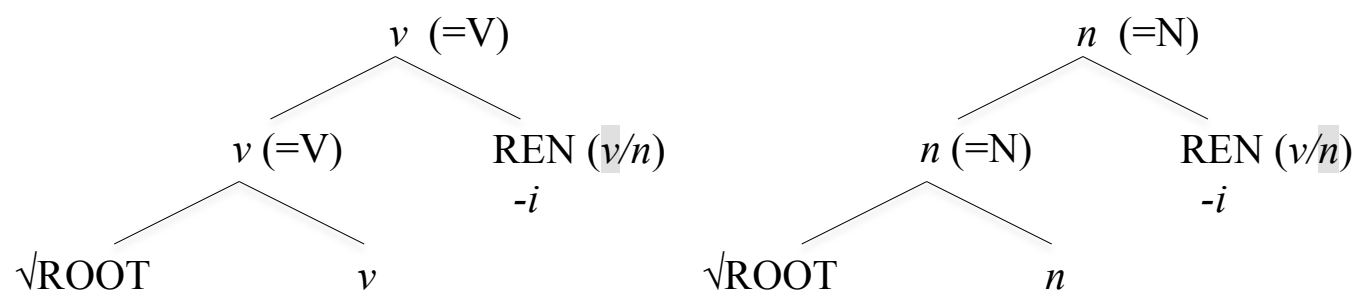

In both (17a) and (17b), renyoo verbs and nouns are only different in terms of their structures in that the category of the REN head is unspecified and is thus assigned a category through agreement with the categorizing head below it (see Sugimura \& Obata 2014 for details, especially for issues with Chomsky's $2013\{\mathrm{H}, \mathrm{H}\}$ labeling).

We depart from our earlier analysis in that renyoo verbs and nouns are rather different structurally, and the REN head does not undergo feature-specification of any sort. However, aside from the feature-specification mechanics, the proposed structure of a renyoo verb in Section 3 shares important ingredients with (17a). Most importantly, the renyoo verb structure, particularly in the case of $\mathrm{V}-\mathrm{V}$ compounds, brings about insightful implications for $\{\mathrm{H}, \mathrm{H}\}$ labeling under Chomsky's (2013) Labeling Algorithm, as pointed out in our earlier work.

According to Chomsky (2013), syntactic objects need to be labeled in order for them to be interpreted at the interfaces. Under Chomsky's Labeling Algorithm, when a head merges with an XP (18a), that head automatically becomes a label by minimal search. When an XP merges with a YP (18b), however, or when a head merges with another head (18c), a problem arises immediately as the labeling algorithm cannot determine the label of such syntactic objects.
a. $\{\mathrm{H}, \mathrm{XP}\}$
b. $\{\mathrm{XP}, \mathrm{YP}\}$
c. $\{\mathrm{H}, \mathrm{H}\}$

Of interest here is an example of V-V-compounds, as briefly introduced in Section 1 and repeated here in (19), which instantiates the case in (18c):

\section{(19) Renyoo Verb Appearing in V-V compounds \\ Aki-ga Hana-o os-i-taos-ta. \\ Aki-NOM Hana-ACC push-REN-topple-PAST \\ 'Aki pushed Hana down.'}

Under the standard analyses, V-V compounds like those in (19) pose a problem for labeling because both heads (i.e. $\mathrm{V}_{1}$ and $\mathrm{V}_{2}$ ) are eligible for labeling, and so the label for the whole compound cannot be determined (see Saito 2013): ${ }^{10}$

\footnotetext{
${ }^{10}$ We focus exclusively on the case of lexical V-V compounds and refrain from discussing syntactic V-V compounds. See Kageyama (1993) for the different natures of these two types of compounds.
} 


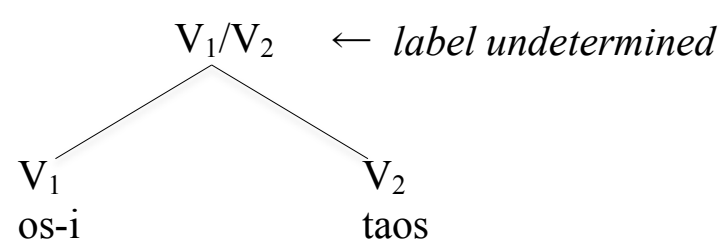

Fortunately, the V-V compound in (19) has the structure in (21) under the current proposal: ${ }^{11}$

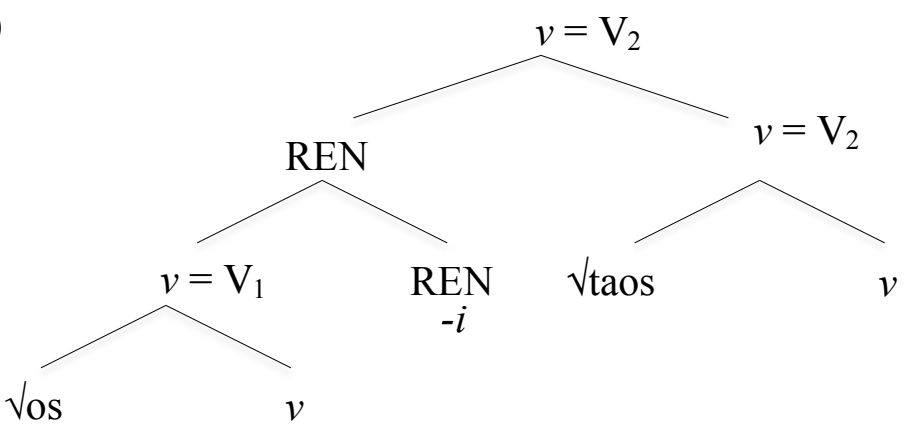

The structure in (21) provides a way of labeling for such $\{\mathrm{H}, \mathrm{H}\}$ cases: the label of the first member of the compound, namely the renyoo verb os- $i$ 'push-REN', is automatically determined through minimal search for a head (i.e. $v$ at the first cycle, REN at the second). As for the labeling of the whole compound, following Rizzi (2014), Sugimura \& Obata (2014) assume that when both heads are equally eligible for labeling the Labeling Algorithm picks out the morphologically simpler head by minimal search. In the current scenario, this means that the second member of the compound taos 'topple' becomes the label because its structure, $[v$ $\sqrt{R O O T} v]$, is simpler than the structure of the renyoo verb os- $i$ 'push-REN', [REN [v $\sqrt{ }$ ROOT $v]$ REN], which is thus detected through minimal search.

One last note to make is why we do not propose an alternative structure for a renyoo verb like (22) instead of (21):

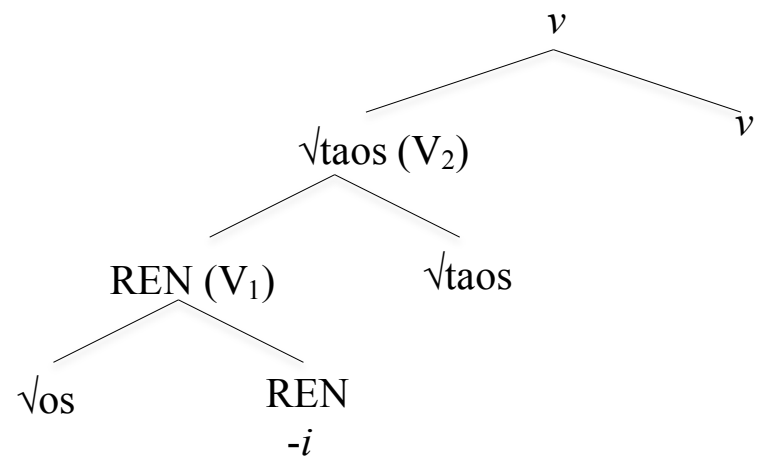

(22) seems to be an equally good candidate for the structure of a $\mathrm{V}-\mathrm{V}$ compound: the [REN

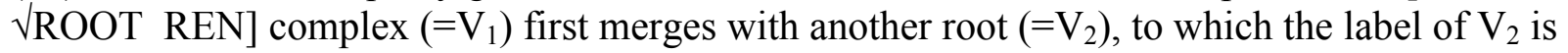

\footnotetext{
${ }^{11}$ Another consequence worthy of note is that the proposed structure crucially assumes the null categorizer $v$ in support of a Distributed Morphology-type analysis (Embick \& Noyer 2007, Halle \& Marantz1993, Harley \& Noyer 1999), but against a Borer (2013)-type analysis, which bans null categorizers altogether (see Sugimura \& Obata 2014).
} 
assigned through minimal search, and that entire syntactic object is then categorized by $v{ }^{12}$ Nevertheless, we have a good reason to reject this alternative. Notice that the alternative structure implies that $\mathrm{V}_{1}$ is never a verb on its own at any derivational stage, which means that a REN head can in principle directly merge with a root. However, as we observed, the productive renyoo forms are only with verbal roots, and as has been confirmed with renyoo nouns, it is not the case that any root can productively appear in its nominal renyoo form. This in itself suggests that the productive renyoo forms (i.e. renyoo verbs) are not formed from roots but from $v(\mathrm{P}) \mathrm{s}$.

5. Conclusion. To conclude, we have proposed that renyoo verbs and nouns, despite their surface similarities, in fact differ from each other structurally. While a renyoo noun is the product of a root directly merging with an $n$ head that is spelled out as the renyoo suffix $-i$, a renyoo verb is the product of a root first merging with an $v$ head and then merging with a REN head. Such structural differences yield the (un)observed effects of semantic idiosyncrasy, productivity, and accent shift when forming a renyoo noun or a verb. We have also explored theoretical implications of the proposed analysis, defending our decomposed structure of a renyoo verb while rejecting an alternative structure from our earlier study (Sugimura \& Obata 2014) based on Chomsky's (2013) Labeling Algorithm, particularly citing an instance of $\{\mathrm{H}, \mathrm{H}\}$ labeling.

\section{References}

Borer, Hagit. 2013. Taking form. Oxford: Oxford University Press.

Chomsky, Noam. 2013. Problems of projection. Lingua 130. 33-49. http://dx.doi.org/10.1016/j.lingua.2012.12.003

Dobler, Eva, Heather Newell, Glyne Piggott, Tobin Skinner, Mina Sugimura \& Lisa Travis. 2009. Narrow syntactic movement after spell-out. Unpublished manuscript. Montreal, QC: McGill University.

Embick, David \& Rolf Noyer. 2007. Distributed morphology and the syntax/morphology interface. In Gillian Ramchand \& Charles Reiss (eds.), The Oxford handbook of linguistic interfaces. 289-324. Oxford: Oxford University Press.

Fodor, Jerry. 1970. Three reasons for not deriving 'kill' from 'cause to die.' Linguistic Inquiry 1. 429-438.

Halle, Morris \& Alec Marantz. 1993. Distributed morphology and the pieces of inflection. In Kenneth Hale \& Samuel J. Keyser (eds.), The view from building 20. 111-176. Cambridge, MA: MIT Press.

Harley, Heidi. 1995. Subjects and clause structure. Cambridge, MA: MIT dissertation.

Harley, Heidi \& Rolf Noyer. 1999. State-of-the-Article: Distributed Morphology. Glot International 4(4). 3-9.

Kageyama, Taro. 1993. Bunpoo-to gokeisei [Grammar and Word Formation]. Tokyo: Hitsuji Press.

Marantz, Alec. 2007. Words and phrases. In Sook-Hee Choe (ed.), Phases in the theory of grammar. 191-222. Seoul: Dong-In Publishing Co.

Miyagawa, Shigeru. 1998. (S)ase as an elsewhere causative and the syntactic nature of words. Journal of Japanese Linguistics 16. 67-110.

Newell, Heather. 2008. Aspects of the morphology and phonology of phrases. Montreal, QC: McGill University dissertation.

\footnotetext{
12 Thanks to Heidi Harley for pointing out this alternative structure.
} 
Rizzi, Luigi. 2014. Cartography, criteria, and labeling. Unpublished manuscript. Geneva: University of Geneva.

Saito, Mamoru. 2013. Case and labeling in a language without $\phi$-feature agreement. Unpublished manuscript. Nagoya: Nanzan University.

Shibatani, Masayoshi. 1990. The languages in Japan. Cambridge: Cambridge University Press.

Sugimura, Mina. 2012. Domain extension: A study of restructuring predicates in Japanese and the role of head movement. Montreal, QC: McGill University dissertation.

Sugimura, Mina \& Miki Obata. 2014. How to label $\{\mathrm{H}, \mathrm{H}\}$ : A view from lexical V-V compounds in Japanese. Paper presented at the $9^{\text {th }}$ International Workshop on Theoretical East Asian Linguistics (TEAL). Nantes, France.

Tagawa, Takumi. 2012. Bunsan-keitairon-o mochiita doosi-katsuyoo-no kenkyuu-ni mukete: Renyookei-no bunseki-ni okeru keitai-toogoron-teki mondai [Towards the Distributed Morphology-based study of verbal conjugation: Morpho-syntactic problems in analyzing renyookei]. In Kenichi Mihara \& Yoshio Nitta (eds.), Katsuyooron-no Zensen [The Frontier of the Theory of Conjugation]. 191-216. Tokyo: Kuroshio Press.

Travis, Lisa. 2000. The L-Syntax/S-Syntax boundary: Evidence from Austronesian. In Ileana Paul, Vivianne Phillips \& Lisa Travis (eds.), Formal issues in Austronesian linguistics. 167194. Dordrecht: Kluwer Academic Publishers.

Tsujimura, Natsuko. 1992. Licensing nominal clauses: The case of deverbal nominal in Japanese. Natural Language \& Linguistic Theory 10. 477-522. http://dx.doi.org/10.1007/BF00133371

Volpe, Mark. 2005. Japanese morphology and its theoretical consequences: Derivational morphology in Distributed Morphology. Stony Brook, NY: Stony Brook University dissertation. 